\title{
Development of Food Formulations for Individual Nutrition
}

\author{
Vladimir Sadovoy ${ }^{1}$, Tatiana Shchedrina ${ }^{2}$, Arcady Silantyev ${ }^{3}$, Magomed Selimov ${ }^{4}$ \\ ${ }^{1}$ Stavropol Technological Institute of Service, Stavropol, Russia; ${ }^{2}$ Pyatigorsk State Technological University, Pyatigorsk, Russia; \\ ${ }^{3}$ Povolzhskiy State University of Telecommunications and Informatics in Stavropol, Stavropol, Russia; ${ }^{4}$ North Caucasus State Tech- \\ nical University, Stavropol, Russia. \\ Email: vsadovoy@yandex.ru
}

Received September $21^{\text {st }}, 2011$; revised November $3^{\text {rd }}, 2011$; accepted November $11^{\text {th }}, 2011$

\begin{abstract}
This paper proposes a method for the developing of nutrition formulations for various population groups categorized by gender, age, body type and nature of labor activity. Meat formulations were developed, taking into account dietitian recommendations, rationality of the amino acid composition, processing characteristics, organoleptic evaluation and cost indicators.
\end{abstract}

Keywords: Nutrition; Balanced Diet; Food Formulation; Individual Nutrition; Optimal Compositions

\section{Introduction}

Adequate nutrition is an essential prerequisite in the set of rehabilitation, recovery, pathology prevention and treatment measures, and is crucial for maintaining health at a high functional level. The medical science has found biological laws of a food, has developed and has proved the concept of a balanced diet of the person, considering its social activity, age, sex and character of work. On the basis of these representations the recommendations about optimum food allowances for various groups of the population are formulated. The reasonable diet is proved and biological bases of a food of the person are developed, for example, in the works [1-3]. The development of food products for individual nutrition begins with the establishment of individual norms not only when it comes to calories, fats, proteins and carbohydrates, but also to a wider range of nutrients (cholesterol, dietary supplements, including antioxidants, fiber, vitamins, minerals, etc.) These norms depend on gender, age, body type, lifestyle, habits, unique characteristics of an individual human body, and the current state of a person's health. There are also numerous specific elements of individual nutrition to be considered. These include, but are not limited to, such features as individual food preferences and allergies, individual digestibility, and the particularities of an individual's digestive system.

The componential composition of the raw materials used for producing meat products is a significant factor in developing modern meat technologies, as it enables us to regulate of nutritional value and functional and processing characteristics of finished products, as well as to forecast the expected therapeutic effect.

\section{Subjects of Research}

We tested raw meat, minced meat samples, finished meat products and other ingredients and materials that are approved by the departments of State Sanitary and Epidemiological Surveillance of the Russian Federation and meet their current normative standards.

\section{Methods}

To improve the efficiency and quality of scientific research we applied mathematical methods of data planning and processing throughout the course of study. The research results analysis was conducted using the following application program packages: Statistic v.6.0, 7.0, 8.0, Statistic Neural Networks (SNN) v.4, and Statistic Automatically Neural Networks Code Generator (SANN) v.8. Data sets were created using the programming language Pascal. Calculations of chemical and amino acid compositions of the projected products were automated using Excel application.

Moisture binding properties of the minced meat samples, as well as the emulsion stability, organoleptic estimation and the output of finished products (\% by mass of raw material) were determined by following the standard practices.

Assessment of balanced amino acid composition of the 
compositions under study was performed by the Lipatov method (developed by Professor N. N. Lipatov, Doctor of Technical Sciences, Academician of Russian Academy of Agricultural Sciences [4]).

\section{Research Findings}

Using body type, weight, gender, age and nature of labor activity as calculation criteria, we determined the energy expenditure and daily intake of key essential ingredients (Table 1), as well as component ratios (animal proteins, animal fats and dietary fiber) for the projected meat products.

Based on the degree of energy expenditure we have allocated 5 labor intensity groups ${ }^{1}$ and developed nutriational standards as the recommended norms of the quantitative consumption of basic nutrients and energy by various population groups in our country. These norms provide a scientific basis for the planning of foodstuffs production and consumption, serve as criteria for assessing dietary intake, and provide the basis for the construction of a balanced diet [5].

Nutritive formulation compositions for the people with a thin body type, in accordance with dietitian recommendations [6], excluded beef fat, beef liver, bacon, pork fat, jowl, skin, and chicken eggs. Planning matrix was converted into actual values, and the input data set was created in the programming language Pascal (Table 2). Similar data sets were created for formulations designed for people with normal body type, people suffering from degree 1, 2, and 3 obesity, and the elderly (dietitian recommendations were taken into account while creating the formulations).

For each data set, amino acid composition of protein component was calculated (Table 3).

To identify raw component compositions containing rational amino acid component, we inserted $\mathrm{FAO} / \mathrm{WHO}$ reference standard indexes into input data set (types of raw materials used) and output data set (amino acid composition of each formulation set). The obtained data was repeatedly subjected to clustering.

As a result we obtained clusters with a small number of variants of formulation sets. Figure 1 shows a diagram comparing the formulations for people with thin body type. Classification trees (or hierarchical trees) shown in Figure 1, allow us to predict which class of categorical variable the objects or observations belong to, based on the respective values of one or more predictor variables. The horizontal tree diagram starts with each object in the class. Gradual (taking very small steps) "weakening" of the criterion (i.e. lowering the threshold that refers to the decision to merge two or more objects into one cluster)

${ }^{1}$ Group 1: mostly nonmanual workers; Group 2: workers engaged in light manual labor; Group 3: workers engaged in manual labor of average intensity; Group 4: workers engaged in heavy manual labor; Group 5: manual workers performing extra heavy labor. results in the formation of new clusters.

As a result, more and more objects are being merged, and the increasing number of clusters is aggregated. Finally, in the last stage all objects are combined together. Compositions which are the closest to the FAO reference standard are the following: 16, 9, 10, 8, 19, 12, 4 .

The color intensity in the diagram (Figure 1) shows the content of each essential amino acid and their combined content in the compositions.

Thus, for example, the quantitative content of essential amino acids for the analyzed compositions (on the axis "X» № 9) varies from 36.0 to 41.0 , which is why the $\mathrm{FAO} / \mathrm{WHO}$ reference standard is shown in darker color. Lysine content (on the axis "X» № 3) varies from 7.6 to 8.1 , well above the FAO reference standard index $(5,5)$, which results in the different color representation in the diagram.

Interpretation of the "latent (i.e. not directly observable) variables", which allow the user to explain the similarities between the given points in the original feature space; with the dimensions of the new feature space is much smaller than that of the original.

An analysis of the spatial arrangement of the version numbers on the chart (Figure 2) revealed 17 compositions, with the most rational, i.e. the closest to the FAO /WHO reference standard, amino acid composition. Analysis of the data showed that among the best compositions are the variants that meet the requirements of people with a thin body type, people suffering from obesity, and seniors.

It should be noted that all variants of meat products compositions are suitable for people with normal body type. For each variant the amino acid composition score of protein component is calculated.

We established a good balance of amino acid composition of the designed compositions. The high amino acid score of lysine (1.33 - 1.47 parts) should be noted, which is consistent with the color scheme of Figure 1. In some samples, the content of tyrosine and phenylalanine is inflated (amino acid score up to 1.47 parts). Mass fraction of essential amino acids used in the biosynthesis of amino acids was $0.0000-0.1912$, and for energy purposes $-0.0000-0.0978$. The utility coefficient $(0.8581-$ $0.9361)$, indexes of "excessive content" of the essential amino acids (2.9783 - 5.3720), and "collatable excessiveness" (2.4585 - 5.9540), also allow us to make conclusions about a well-balanced amino acid composition of proteins in the designed compositions.

Despite the fact that all samples are manufactured within the same processing mode, their qualitative characteristics vary widely: the moisture-binding properties ranged from 76.0 to $100.0 \%$ of the total moisture; emulsion stability varied in the range of $6.3-92,1 \%$; the average organoleptic score was in the range of $3.5-4.9$ points; the output of finished goods amounted to 117.5 - 


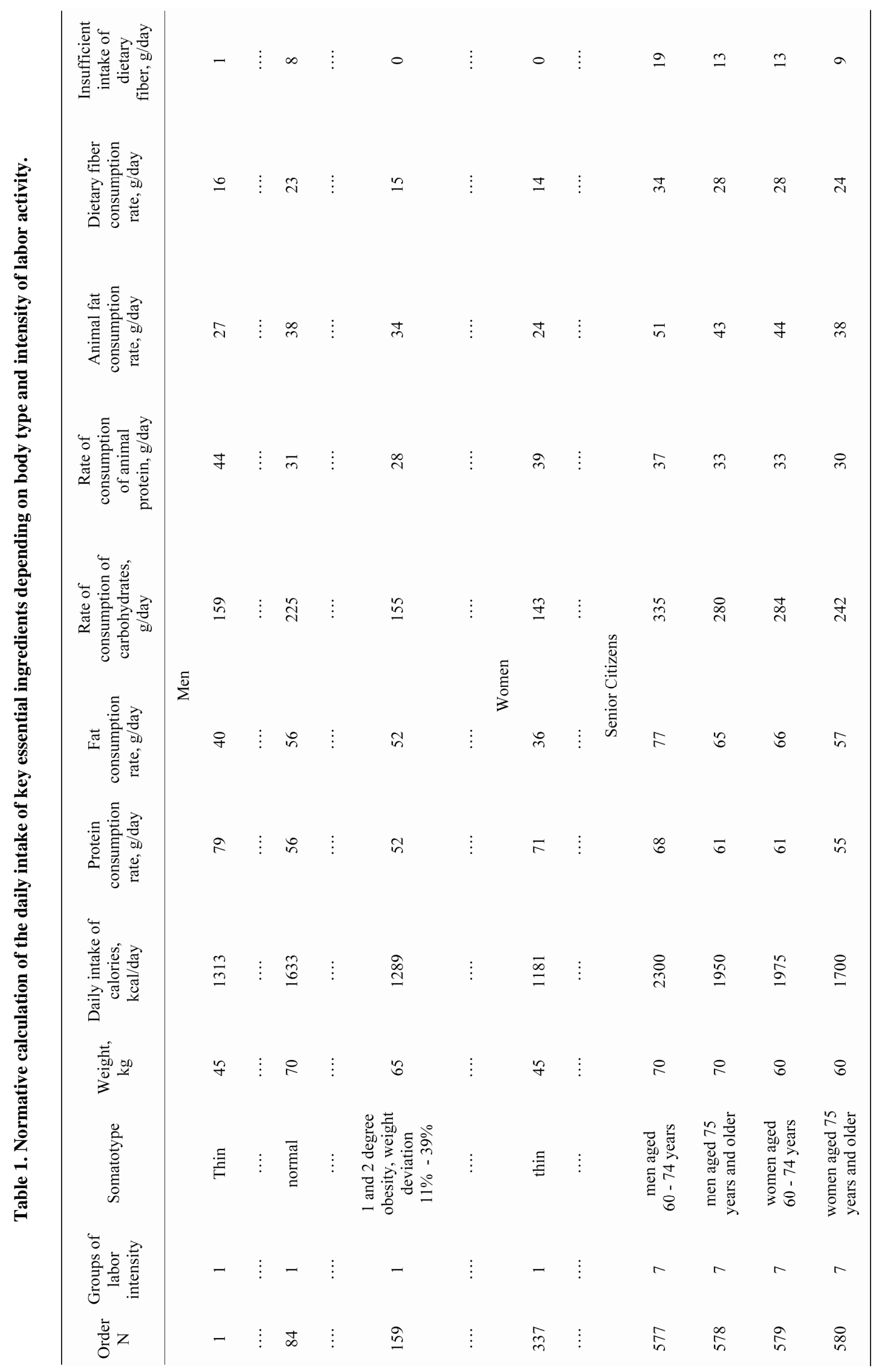


Table 2. Formulation component set for people with thin body type.

\begin{tabular}{|c|c|c|c|c|c|c|c|c|c|}
\hline \multirow{2}{*}{$\begin{array}{l}\text { Version number in } \\
\text { the data }\end{array}$} & \multicolumn{3}{|c|}{ Cut beef } & \multicolumn{2}{|c|}{ Cut pork } & \multirow{2}{*}{ Gelatin } & \multirow{2}{*}{ Sodium caseinate } & \multirow{2}{*}{ Whey Protein } & \multirow{2}{*}{ Animal protein } \\
\hline & grade 1 & grade 2 & Fatty beef & Semi-fat & Fatty & & & & \\
\hline 1 & 29.4 & 38.4 & 6.0 & 10.3 & 14.1 & 1.4 & 0.4 & 0.1 & 0.0 \\
\hline 2 & 15.2 & 40.2 & 6.1 & 22.4 & 14.7 & 0.4 & 0.6 & 0.5 & 0.6 \\
\hline$\cdots$ & $\cdots$ & $\cdots$ & $\cdots$ & $\cdots \cdot$ & $\cdots$ & $\cdots$ & $\cdots$ & $\cdots$ & $\cdots$ \\
\hline$\cdots$ & $\cdots$ & $\cdots$ & $\cdots$ & $\cdots$ & $\cdots$ & $\cdots$ & $\cdots$ & $\cdots$ & $\cdots$ \\
\hline 16,732 & 97.1 & 0.0 & 0.0 & 0.0 & 0.0 & 0.0 & 2.9 & 0.1 & 0.0 \\
\hline 16,733 & 97.1 & 0.0 & 0.0 & 0.0 & 0.0 & 0.0 & 0.0 & 0.4 & 2.9 \\
\hline$\cdots$ & $\cdots$ & $\cdots$ & $\cdots$ & $\cdots$ & $\cdots$ & $\cdots$ & $\cdots$ & $\cdots$ & $\cdots$ \\
\hline
\end{tabular}

Table 3. Amino acid composition of the formulations data sets for people with a thin body type.

\begin{tabular}{|c|c|c|c|c|c|c|c|c|c|}
\hline $\begin{array}{l}\text { Order } \\
\text { number in } \\
\text { the data set }\end{array}$ & $\begin{array}{l}\text { Isoleucine, } \\
\mathrm{g} / 100 \mathrm{~g} \\
\text { protein }\end{array}$ & $\begin{array}{l}\text { Leucine, } \\
\mathrm{g} / 100 \mathrm{~g} \\
\text { protein }\end{array}$ & $\begin{array}{l}\text { Lysine, } \\
\mathrm{g} / 100 \mathrm{~g} \\
\text { protein }\end{array}$ & $\begin{array}{c}\text { Methionine }+ \\
\text { cystine, } \mathrm{g} / 100 \mathrm{~g} \\
\text { protein }\end{array}$ & $\begin{array}{l}\text { Phenylalanine }+ \\
\text { tyrosine, } \mathrm{g} / 100 \mathrm{~g} \\
\text { protein }\end{array}$ & $\begin{array}{l}\text { Threonine, } \\
\mathrm{g} / 100 \mathrm{~g} \\
\text { protein }\end{array}$ & $\begin{array}{l}\text { Tryptophan, } \\
\mathrm{g} / 100 \mathrm{~g} \\
\text { protein }\end{array}$ & $\begin{array}{l}\text { Valine, } \\
\mathrm{g} / 100 \mathrm{~g} \\
\text { protein }\end{array}$ & $\begin{array}{l}\text { The amount of } \\
\text { essential amino } \\
\text { acids, g/100 g protein }\end{array}$ \\
\hline 1 & 4.41 & 8.00 & 8.22 & 3.82 & 7.78 & 4.35 & 1.16 & 5.55 & 43.29 \\
\hline 2 & 4.38 & 7.87 & 8.22 & 3.78 & 7.55 & 4.37 & 1.16 & 5.56 & 42.89 \\
\hline$\ldots$ & $\ldots$ & $\ldots$ & $\ldots$ & $\ldots$ & $\ldots$ & $\ldots$ & $\ldots$ & $\ldots$ & $\ldots$ \\
\hline 314 & 4.33 & 7.70 & 8.13 & 3.67 & 7.38 & 4.31 & 1.15 & 5.50 & 42.17 \\
\hline$\ldots$ & $\ldots$ & $\ldots$ & $\ldots$ & $\ldots$ & $\ldots$ & $\ldots$ & $\ldots$ & $\ldots$ & $\ldots$ \\
\hline 16,732 & 4.32 & 8.07 & 8.33 & 3.99 & 8.26 & 4.37 & 1.17 & 5.76 & 44.27 \\
\hline 16,733 & 3.89 & 7.30 & 7.83 & 3.57 & 7.05 & 3.98 & 0.97 & 5.20 & 39.80 \\
\hline$\ldots$ & $\ldots$. & $\ldots$ & $\ldots$ & $\ldots$ & $\ldots$ & $\ldots$ & $\ldots$ & $\ldots$. & $\ldots$ \\
\hline
\end{tabular}

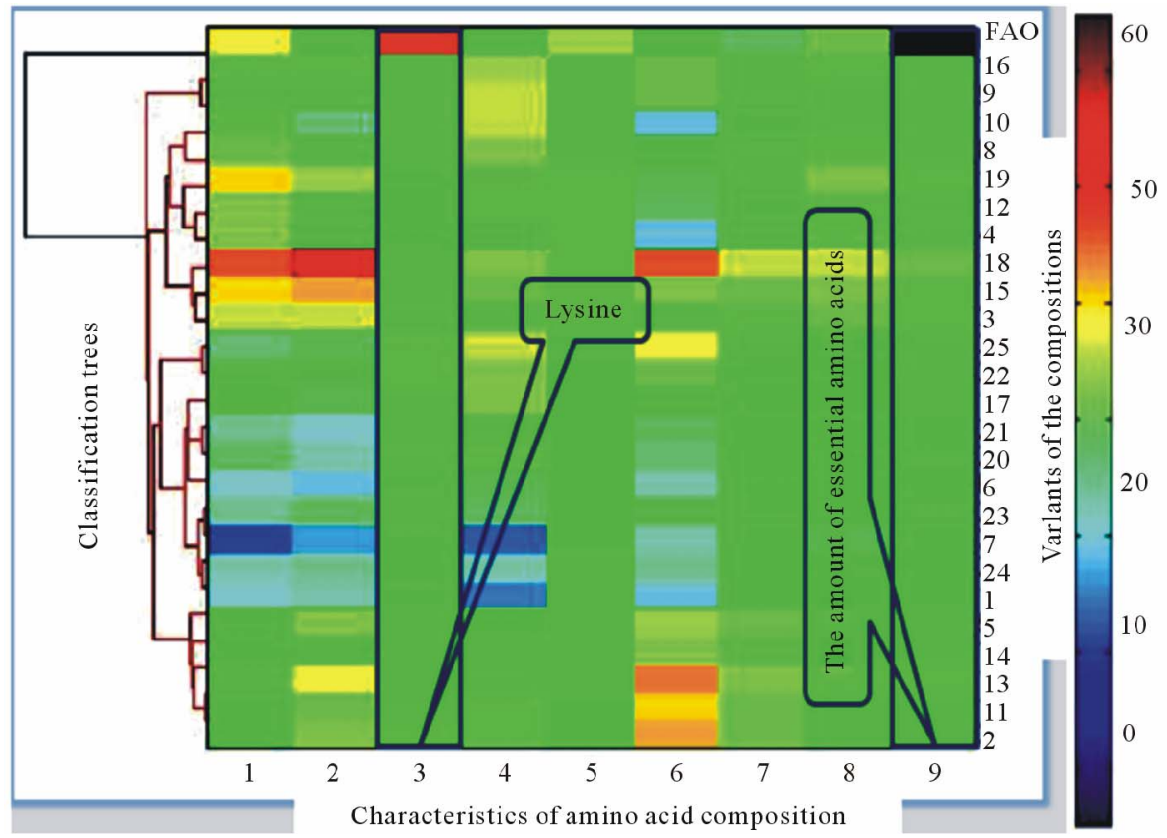

Figure 1. Clustering of compositions for people with thin body type. (On the axis " $X$ " on the diagram shows the characteristic amino acid composition of songs (1. isoleucine, 2. leucine, 3. lysine, 4. methionine + cystine, 5 . phenylalanine, tyrosine+, 6 . threonine, 7. tryptophan, 8. valine, 9 . amount of essential amino acids)). 


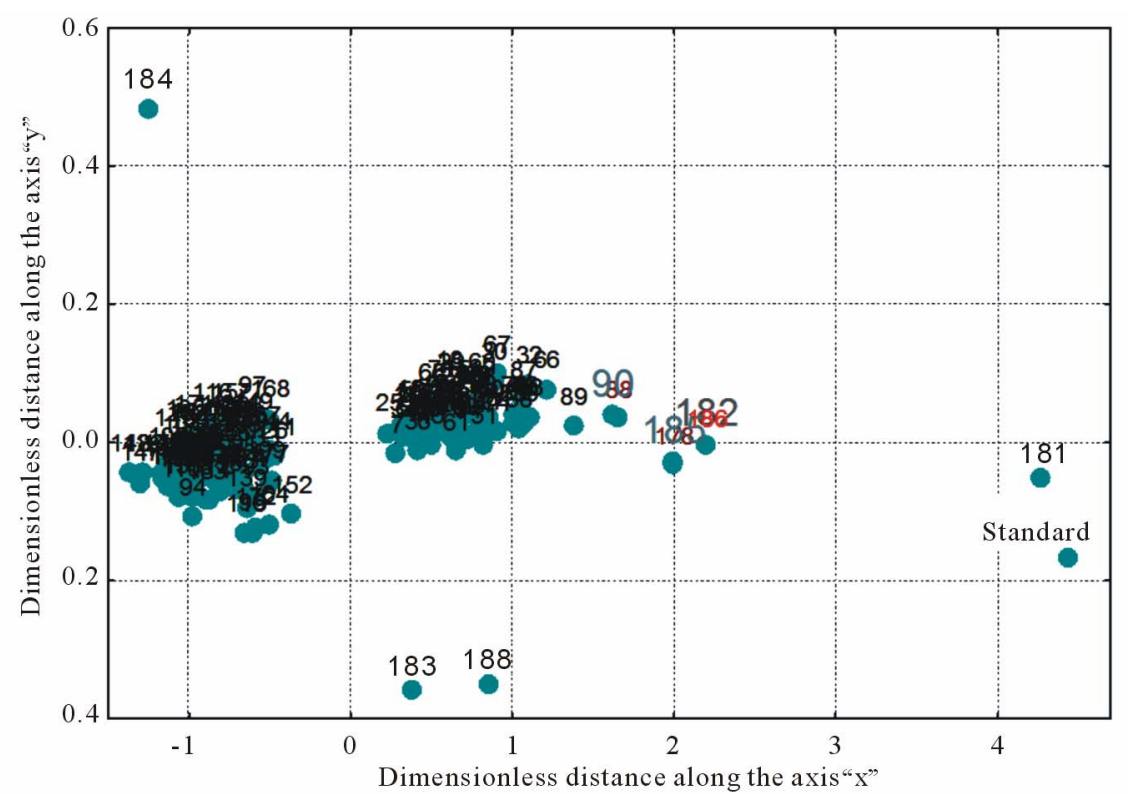

Figure 2. Identification of rational amino acid compositions.

$142.3 \%$ of the main raw material mass; the wholesale price of utilized raw materials ranged from 5258.33 to 11104.54 rub per $100 \mathrm{~kg}$ of finished product.

Due to the fact that there is a set of necessary requirements laid out for the production of cooked sausage products (dietitian recommendations, the rationality of the amino acid composition and processing characteristics, organoleptic characteristics and cost parameters), the choice of products for specific population group should be determined by taking into account the properties of the desired products, as well as numerous specific factors and correlations that define end goals, the purpose and the usage of produced goods.

To select the optimal variant from the multiplicity of possible variants we define the particular criteria of the alternatives under comparison. These criteria should reflect the requirements for the projected formulations that are not equal in their "weight" or importance $\left(C_{i}\right)$. In addition, various types of formulations meet the requirements to a different degree. This is solved by introducing a weight coefficient $b_{i j}$, which determines the extent to which version $j$ fits requirement $i$, calculated using the modified rank method [7].

To process the data which is not easily subjected to formalization, the method of expert evaluation has been widely used in the recent time. This method allows obtaining an objective estimation on the basis of subjective data provided by experts. Complex partial criterion weight $C_{i} \times b_{i j}$ is the product of two weights which are determined using the data is obtained from expert surveys.

The amount of points for each variant of compositions is determined by the modified rank method, where an expert analysis is carried out to assess the extent to which each option fits the requirements.

To calculate the integral criterion of the compared alternatives $F 2=\sum_{i=1}^{n} c_{i} \times b_{i j}$ it is necessary to sum all the products $c_{i} \times b_{i j}$ of each of $j$ rows of solutions matrix. The result of this summation is a "efficiency indicator".

The optimal formulation, i.e. the best in terms of the given set of requirements will be the formulation with the maximal value of the efficiency indicator.

Based on the efficiency evaluation of component composition performed using the methods of expert evaluation, paired comparison, and the modified rank method, we detected the basic formulations for cooked sausage products suitable for consumption by various population groups. The developed compositions are consistent with the dietitian recommendations; they feature rational amino acid composition and cost indicators, as well as good organoleptic properties.

\section{REFERENCES}

[1] M. J. Bejul, V. N. Budagovskaja, V. G. Vysotsky, et al., "Manual on Dietologies," in Russian, In: M. A. Samsonov and A. A. Pokrovsky, Eds., Medicine, 1992, p. 464.

[2] A. F. Doronin and B. A. Shenderov, "Functional Nutrition," in Russian, Grant, Moscow, 2002, p. 250.

[3] S. M. Evenshtejn, "Popular Dietology," in Russian, Economics, Moscow, 1990, p. 321.

[4] N. N. Lipatov, "Principles of Composition Design and Improvement of Multicomponent," Meat and Dairy Products Technologies: Defence of a Doctorate in Technical Sciences, The State Institute for the Meat and Dairy Technologies, Moscow, 1988, p. 54. 
[5] M. A. Samsonov and A. A. Pokrovsky, "Reference Book on Dietology," Meditsina, Moscow, 1992, p. 464.

[6] A. K. Baturin, et al., "Normative Standards of Physiological Energy and Nutrients Needs for Various Population Groups of Russian Federation," Method Guidelines,
Russian Academy of Sciences, Moscow, 2008.

[7] F. Aleksandrova, "Methods for Selecting the Optimal Technical Equipment Using the Solutions Matrix," Materials for the All-Union Conference of Mechanics "Automated Machinery-79”, Tambov, 1979, p. 523. 